\title{
Red de Turismo Sur Austral: Potenciando el Turismo en la Región de Los Lagos
}

\author{
Claudio Muñoz Pereira \\ Director Ejecutivo \\ Red de Turismo Sur Austral
}

Con dos años de existencia la Red de Turismo Sur Austral ha logrado convertirse en una organización intersectorial importante en el ámbito de la formación de recursos humanos, con miras a fortalecer el desarrollo de la actividad turística en la zona.

Esta es una iniciativa que se inserta en el marco del Programa ChileCalifica de los Ministerios de Educación, Trabajo y Economía donde se cuenta con la participación de instituciones educativas y empresariales de diversas ciudades de la Región, su trabajo en la zona se realiza bajo el liderazgo de la Universidad Austral de Chile.

Desde su creación su objetivo fundamental fue contribuir al fortalecimiento del turismo como polo de desarrollo regional, mediante un trabajo conjunto del sector productivo y educacional ligado a esta actividad. Para ello se trabaja en el diseño e implementación de modelos curriculares articulados dirigidos a los recursos humanos del sector turístico, con el propósito de mejorar la calidad de los servicios en este sector.

En la Región se realizó una evaluación de los servicios turísticos, donde se determinó la necesidad de satisfacer debilidades en la gestión y desarrollo del negocio que entregan las empresas del rubro, hecho que repercute en los servicios que a diario los empresarios ofrecen a los visitantes que viajan hasta el sur para conocer los atributos culturales y las bellezas naturales de la zona.

Para enfrentar este desafío de manera concreta, la Red de Turismo Sur Austral contempla entre sus socios a instituciones educativas y productivas, con el fin de unir esfuerzos para obtener una coherencia en la formación educacional de nivel medio con la educación Técnico Superior y las Universidades. 
A esto se suma las diferentes capacitaciones realizadas a recursos humanos de la Región. En este contexto se han efectuado distintas actividades como la edición y distribución de boletines informativos, cursos de perfeccionamiento docente, cursos de inglés, encuentros, capacitación en temas como atención al cliente y otros más que están por venir.

Entre los hitos del último tiempo, se aprobó la licitación del Plan Estratégico de la Red, con el propósito de programar y proyectar el quehacer de esta organización para los próximos años, unificando para ello ciertos criterios y potenciando la generación de nuevas capacidades (prestación de servicios como ente articulado, por ejemplo), de personalidad jurídica y de financiamiento externo, además de sustentabilidad en el tiempo.

La Red de Turismo Sur Austral está integrada por la Universidad Austral de Chile, Universidad de Los Lagos, cuatro Corporaciones y Cámaras de Comercio de la Región, trece Liceos de Enseñanza Técnico Profesional en el área del Turismo y tres Centros de Formación Técnica, además de las municipalidades de Valdivia, Puerto Octay y Frutillar.

El nacimiento de esta iniciativa dice relación a los desafíos asumidos por Chile para enfrentar el desarrollo tecnológico-productivo, que exige cada día una capacitación permanente a las personas para enfrentar la dinámica del empleo. En este contexto, surge la idea de desarrollar Itinerarios de Formación Técnica en el sector turismo que respondan a las demandas del mundo del trabajo.

Para alcanzar esta meta es necesario establecer una articulación permanente y participativa entre el sistema educacional y el sector productivo. Los itinerarios de formación técnica son definidos como programas que están conectados en forma secuencial (verticalmente) y que consideran homologaciones entre modalidades y experiencias formativas que se ubican en un mismo nivel (horizontalmente).

Aquí es fundamental considerar el enfoque de competencias laborales, donde se identifican los criterios considerados idóneos para ejecutar una actividad productiva denominados aprendizajes esperados. Este es un elemento que permite dotar de pertinencia al diseño curricular basado en módulos que se busca construir.

Para la elaboración del diseño curricular se requiere establecer un flujo de información que permita responder al objetivo final. El punto de inicio generalmente lo constituye el perfil de egreso para la especialidad técnica de nivel superior, tal como lo resume el diagrama en la pagina siguiente: 


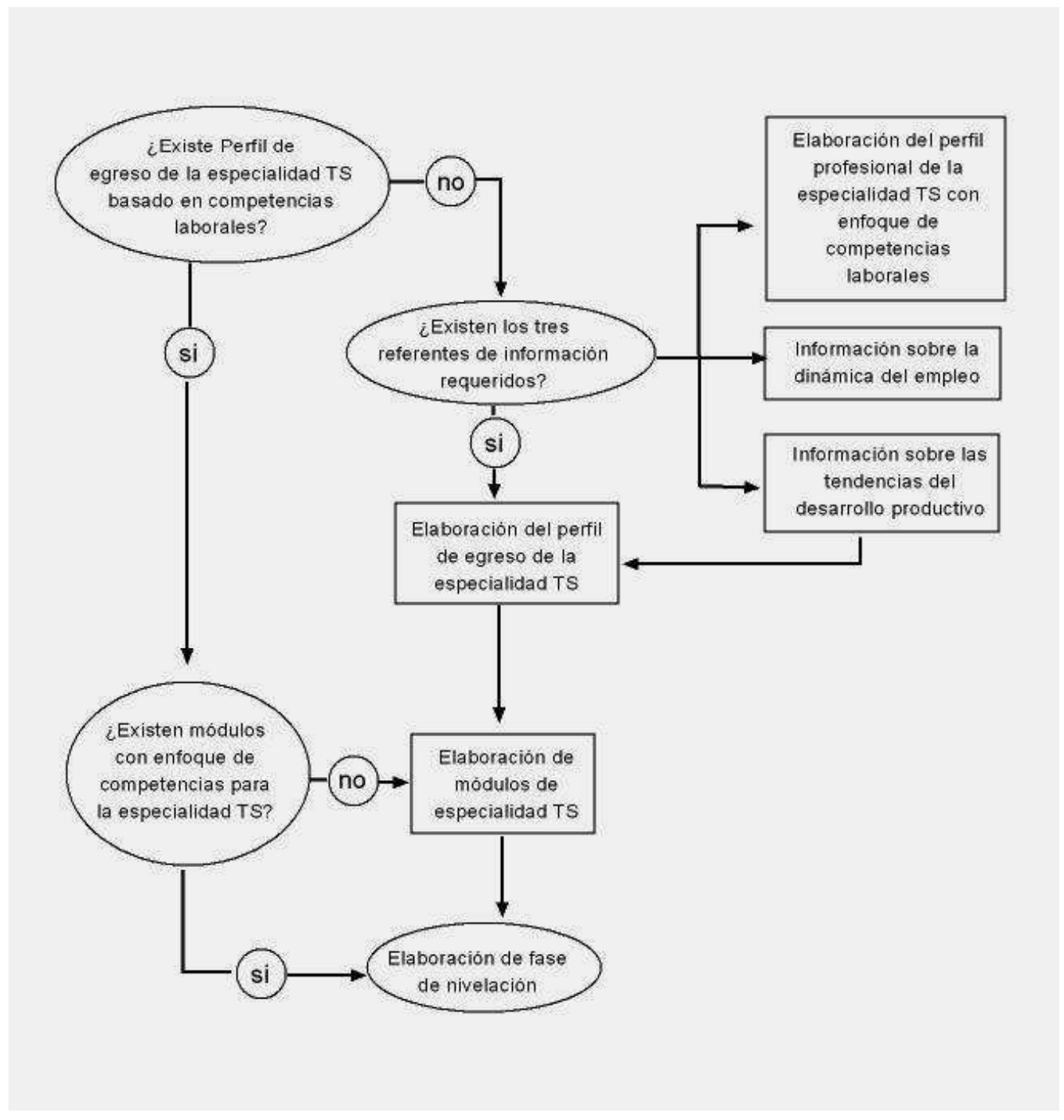

Fuente: Programa Chilecalifica. Diseño de Itinerarios para la Formación Técnica

Para avanzar en el diseño curricular basado en competencias se hace necesario definir también el perfil profesional, el que constituye un conjunto de competencias laborales de la figura profesional que se pretende construir. El perfil profesional debe ser definido por el sector productivo correspondiente y no por el sistema educativo. Basándose en esta metodología, el sector productivo será quien señale los profesionales que necesita acorde a sus propios requerimientos, por lo que los egresados del sistema formativo que eduque bajo este prisma tendrán las oportunidades claras de empleo en aquellos trabajos para los que han sido formados. 
RELACION ENTRE PERFIL PROFESIONAL Y PERFIL DE EGRESO

PROGRAMA FORMATIVO

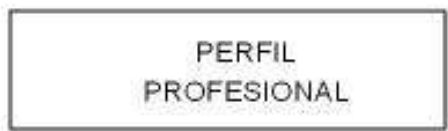

PERFIL

DE EGRESO

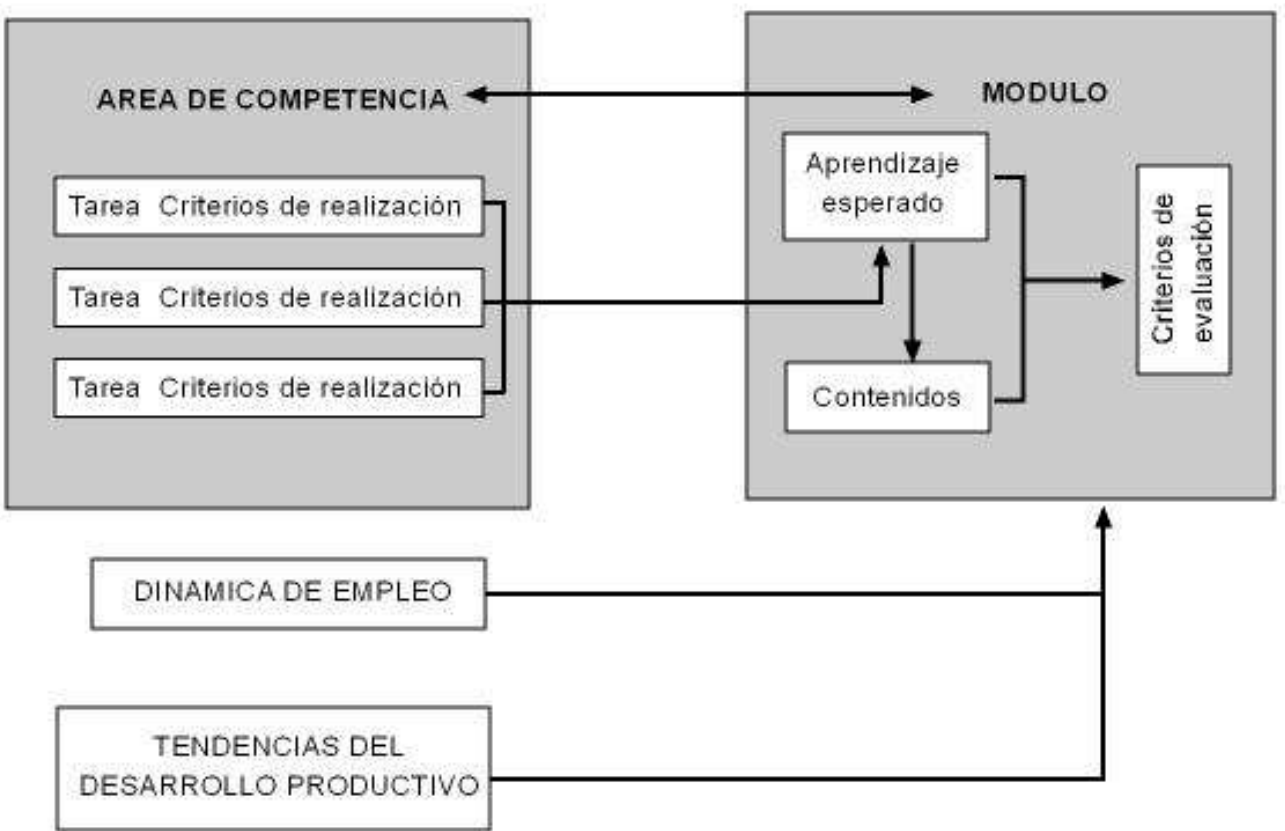

\section{LINEAS DE ACCION}

Para el logro de los objetivos fundamentales de la Red de Turismo Sur Astral y su proyecto se definieron distintas líneas de acción dirigidas a consolidar un trabajo coordinado y coherente con las necesidades de los empresarios turísticos de la zona.

Las líneas de acción son:

\section{1.- Itinerario para la formación Técnica y la Educación Continua:}

Su meta es formular y poner en práctica, en conjunto con el sector productivo, un itinerario curricular articulado que considere los tres niveles de educación: Enseñanza Media Técnica Profesional, Centros de Formación Técnica y Universidades. Hoy, se está previendo, a la luz de la asistencia técnica contratada por la Red, el incorporar aspectos relativos al nivel de oficio en dicho itinerario. Se constituye, por lo tanto, en la columna vertebral y línea de acción primordial del proyecto. 


\section{2.- Recursos didácticos y estrategias de transferencia:}

Cuyo objetivo es diseñar materiales educativos a objeto de facilitar y mediar tanto los aprendizajes de los alumnos como el perfeccionamiento de los docentes, con el uso y aplicación de nuevas tecnologías en los procesos de aprendizaje.

\section{3. - Mejoramiento de la calidad docente y estrategias de transferencia:}

Su objetivo principal es generar un proceso de perfeccionamiento docente y modelos de transferencia pedagógica entre los miembros de la Red, acorde a las necesidades de formación definidas en la configuración de itinerarios.

\section{4. - Centro de Evaluación de Competencias y Educación Continua:}

Su objetivo dice relación con el generar un Centro de Evaluación de Competencias y Educación Continua capaz de satisfacer las demandas en esta materia en el marco de la legislación que se prepara en dicho ámbito.

\section{5. -Apoyo al mejoramiento de la calidad:}

Cuya meta es habilitar y dotar, de mobiliario y equipos necesarios para laboratorios, talleres y aulas demostrativas, según las necesidades de los establecimientos de la Red y de acuerdo a las necesidades del perfil levantado en las actividades desarrolladas al alero de la línea 1.

\section{ASISTENCIA TÉCNICA CONSULTORA DEL PAIS VASCO}

En al marco de las actividades de la línea 1 ya enunciada, la consultora española Prodeso S. Coop es la responsable de desarrollar la asesoría técnica a la Red de turismo Sur Austral con el fin de trabajar en el diseño de un currículo de formación técnica en el sector turismo, área gastronómica, con una duración de 8 meses, a partir de diciembre de 2005.

PRODESO S. Coop., de Mondragón Corporación Corporativa, es un consorcio constituido en 1998 para el desarrollo de proyectos de cooperación internacional. Su objetivo es transformarse en un vehículo de transferencia que articula las diferentes capacidades y experiencias desarrolladas a lo largo de historia.

Para ello cuenta con un staff de apoyo en diferentes ámbitos relacionados directamente a la educación. PRODESO dispone de una vasta experiencia en asistencia técnica, tanto en 
Chile como en otros países de Latinoamérica y, por cierto, en la propia España, siendo seleccionada para llevar adelante el proyecto referido a la Red de Turismo Sur Austral, en el marco de una licitación nacional e internacional llevada a cabo para estos efectos.

La idea es desarrollar un trabajo con la participación de todos los socios de la Red desde Panguipulli, por el norte, hasta Palena, por el sur, con el propósito de elaborar un currículo de formación en el área gastronómica, tanto a nivel de oficio, como de enseñanza media, técnico profesional e incluso universitaria, respondiendo a los requerimientos del sector productivo mediante una formación basada en competencias.

Con esto se espera que, a futuro, cuando se aplique el currículo que se diseñará y existan personas tituladas mediante esta modalidad, "el sector productivo podrá contar con profesionales bien formados dispuestos a trabajar de inmediato, que están formados en función de las propias necesidades del área, beneficiando a toda la Red compuesta por el ámbito educativo y productivo de la Región"

De esta forma se toma fundamental establecer, para el desarrollo de esta asistencia técnica, lazos de comunicación e intercambio de ideas y experiencias que potencien los resultados y garanticen la calidad y pertinencia los productos elaborados.

Para finalizar, se hace necesario señalar que la Red de Turismo Sur Austral convoca a un gran desafío a los dos sectores, educacional y productivo, que en oportunidades parecen divorciarse de sus intereses y metas comunes. Esta nueva organización participativa llama a sus socios a trabajar en conjunto y buscar soluciones a los problemas, permitiendo así mejores oportunidades para los futuros y actuales trabajadores, además de potenciar en profundidad la calidad de los servicios para consolidar el desarrollo del turismo en la Región de Los Lagos. 